\title{
Pengembangan Lembar Kerja Siswa (LKS) dan Rencana Pelaksanaan Pembelajaran (RPP) Materi Perbandingan dan Skala Berbasis Scientific Approach yang Berorientasi Problem Based Learning (Development of Students Worksheet and Lesson Plan for Ratio and Scale Materials based on Scientific Approach with Problem Based Learning Orientation)
}

Dhika Elvira Maylistiyana, Hobri, Susanto

Program Studi Pendidikan Matematika, Jurusan Pendidikan MIPA, FKIP, Universitas Jember (UNEJ)

Jln. Kalimantan 37, Jember 68121

E-mail: hobri1973@gmail.com

\begin{abstract}
Abstrak
Tujuan penelitian ini adalah untuk menghasilkan Lembar Kerja Siswa (LKS) dan Rencana Pelaksanaan Pembelajaran (RPP) pada materi perbandingan dan skala berbasis Scientific Approach berorientasi Problem Based Learning yang valid, praktis dan efektif. Jenis penelitian yang digunakan adalah model penelitian pengembangan Plomp. Tahap-tahap yang dilalui untuk mendapatkan LKS dan RPP yang valid, praktis dan efektif antara lain, (1) tahap investigasi awal; (2) tahap perancangan; (3) tahap realisasi; (4) tahap tes, evaluasi, dan revisi; (5) tahap implementasi. Materi pembelajaran yang dikembangkan adalah perbandingan dan skala. Ujicoba dilakukan pada siswa kelas VIIA SMP Negeri 1 Jenggawah. Instrumen yang digunakan adalah instrumen validasi LKS, RPP, dan THB; instrumen observasi aktivitas guru, instrumen observasi aktivitas siswa, dan lembar angket respon siswa. Pengembangan LKS dan RPP berbasis Scientific Approach yang berorientasi Problem Based Learning mempunyai koefisien validitas sebesar 0,91 untuk RPP; 0,93 untuk LKS; dan 0,91 untuk THB. Tingkat pencapaian aktivitas guru pada pertemuan pertama hingga pertemuan keempat berturut-turut: $90,8 \%, 89,2 \%, 87,5 \%$, dan 90\% dengan kategori baik pada setiap pertemuan. Persentase aktivitas siswa pada pertemuan pertama hingga pertemuan keempat berturutturut: $81,3 \%, 88,5 \%, 89,1 \%$, dan $91,1 \%$, sehingga persentase aktivitas siswa pada keempat pertemuan dapat dikategorikan baik. Dari analisis data THB diperoleh data ketuntasan hasil belajar $80 \%$ siswa yang mengikuti pembelajaran mampu mencapai tingkat penguasaan materi skor minimal 68. Sedangkan dari analisis angket respon siswa diperoleh persentase sebesar $81 \%$ siswa yang memberi respon positif. Maka pengembangan LKS dan RPP materi perbandingan dan skala berbasis Scientific Approach yang berorientasi Problem Based Learning telah memenuhi kevalidan, kepraktisan, dan keefektifan.
\end{abstract}

Kata Kunci: Model pengembangan Plomp, Scientific Approach, Problem Based Learning

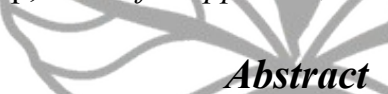

The purpose of the research is to provide Student Worksheet and Lesson Plans on Scale and Ratio based of Scientific Approach which oriented on Problem based Learning that is valid, practical and efective. Type of research conducted was the Plomp development models. Steps performed to obtain Students Worksheet and Lesson Plan that is valid, practical and efective were: (1) Early investigation stage; (2) desaining stage; (3) realization stage; (4) test stage, evaluation and revision; (5) implementation stage. Learning materials developed were scale and ratio. Test performed on students of class VIIA Jenggawah Junior High School. Intruments used were validation instrument of Student Worksheet, Lesson Plan, and Evaluation Test; instrument observation of teacher's activities, observation of students' activities and students' questionnaire result.Development of students worksheet and lesson plan based on Scientific Approach with Problem Based Learning orientation has the validity coeficient of 0.91 for lesson plan; 0.93 for students workseet; and 0.91 for evaluation result test. The level of achievement of teachers' activities during first meeting until fourth meeting in a row were: $90.8 \%$, $89.2 \%, 87.5 \%$ and $90 \%$ with good category on every meeting. Percentage of the students' activities during first meeting until fourth meeting in a row were: $81.3 \%, 88.5 \%, 89.1 \%$ and $91.1 \%$, therefore percentage of students' activities during four meetings can be categorized good. From THB data analysis obtained study test achievement data of $80 \%$ students whom following studying process managed to achieve level of material understanding score of 68. Meanwhile from the analysis of the student's response obtained percentage of $81 \%$ students whom gave positive response. Therefore, development of student worksheets and lesson plan of comparison and scale materials based on Scientific Approach which oriented on Problem Based Learning already fulfilled the validity, practicality and effectifity standards.

Keywords: Plomp development models, Scientific Approach, Problem Based Learning

\section{Pendahuluan}

Salah satu fungsi lembaga pendidikan (sekolah) digunakan sebagai "pintu gerbang" untuk menghadapi berbagai tuntutan masyarakat. Oleh sebab itu, pemerintah telah mengambil langkah-langkah nyata melalui pembaharuan (inovasi) pendidikan. Pembaharuan tersebut khususnya berkaitan dengan kurikulum dan metode pembelajaran[1]. 
Pembaharuan kurikulum telah dilakukan oleh Kementerian Pendidikan dan Kebudayaan yang menciptakan sebuah kurikulum baru yaitu kurikulum 2013 yang dirancang untuk menggantikan Kurikulum Tingkat Satuan Pendidikan (KTSP 2006).

Kurikulum 2013 bertujuan untuk mempersiapkan manusia Indonesia agar memiliki kemampuan hidup sebagai pribadi dan warga negara yang beriman, produktif, kreatif, inovatif, serta efektif. Kurikulum 2013 juga mampu berkontribusi pada kehidupan bermasyarakat, berbangsa, bernegara, dan peradaban dunia[2]. Kurikulum 2013 berbasis karakter, artinya lebih mengutamakan pemahaman, dan keterampilan siswa. Siswa dituntut untuk memahami materi, aktif berdiskusi dan presentasi, serta memiliki sopan santun disiplin yang tinggi.

Implementasi kurikulum 2013 sangat jauh dari tujuan yang diharapkan. Kurangnya koordinasi antara pusat dan daerah, serta peraturan Menteri Pendidikan dan Kebudayaan, panduan teknis, dan modul pelatihan yang kurang sesuai. Masa penulisan buku pendukung kurikulum 2013 juga dapat dikatakan terburu-buru dan tanpa standar penulisan yang jelas, pelatihan guru yang tidak dipersiapkan dengan baik, dan distribusi buku yang mengalami banyak kendala.

Pendekatan pembelajaran yang sesuai dengan kurikulum 2013 adalah Scientific Approach dengan pembelajaran yang berpusat pada siswa. Sudarwan [3] mengemukakan bahwa:

Pendekatan scientific merupakan suatu pendekatan yang menekankan pada dimensi pengamatan, penalaran, penemuan, pengabsahan, dan penjelasan tentang suatu kebenaran. Dengan demikian, proses pembelajaran harus dilaksanakan dengan dipandu nilai-nilai, prinsip-prinsip, atau kriteria ilmiah yang meliputi berbagai keterampilan yang harus dikembangkan guru meliputi kegiatan mengamati, menanya, menalar, mencoba, mengolah, menyimpulkan, menyajikan dan mengkomunikasikan.

Berdasarkan tuntutan kurikulum tersebut, guru harus dapat menerapkan Scientific Approach dalam kegiatan pembelajaran. Guru harus memfasilitasi siswa untuk mengembangkan berbagai keterampilan ilmiah sehingga siswa dapat menemukan sendiri pengetahuannya melalui interaksi dalam belajar. Meskipun pemerintah telah memberikan bahan ajar berupa buku, guru masih mengalami kesulitan dalam mengembangkan dan menerapkan Scientific Approach yang cukup kompleks. Maka dari itu dengan adanya kurikulum 2013 sangat memerlukan guru yang kreatif dan inovatif dalam mengembangkan dan melaksanakan bahan ajar yang dapat diimplementasikan dalam proses pembelajaran [4].

Melihat banyaknya kekurangan mengenai bahan ajar berupa Lembar Kerja Siswa (LKS) yang diberikan pada siswa serta Rencana Pelaksanaan Pembelajaran (RPP) yang digunakan oleh guru, maka diperlukan adanya suatu Lembar Kerja Siswa (LKS) yang dirancang untuk memfasilitasi siswa dalam mengembangkan berbagai aspek keterampilan dan Rencana Pelaksanaan Pembelajaran (RPP) yang sesuai dengan Scientific Approach, meliputi mengamati, menanya, menalar, mencoba, dan mengomunikasikan. Pembelajaran yang dilakukan oleh guru biasanya menggunakan model pembelajaran Problem Based Learning (PBL) untuk mendorong kemampuan siswa dalam penerapan Scientific Approach. Problem Based Learning (PBL) merupakan model pembelajaran berbasis masalah yang menuntut siswa untuk bekerja sama secara aktif dalam mencari jawaban atas masalah yang diberikan oleh guru. Pembelajaran berbasis masalah ini bertujuan agar siswa dapat meningkatkan prestasi, dan sikap siswa.

Dengan demikian, perlu dilakukan pengembangan terhadap Lembar Kerja Siswa (LKS) dan Rencana Pelaksanaan Pembelajaran (RPP) berbasis Scientific Approach berorientasi Problem Based Learning.

\section{Metode Penelitian}

Model penelitian pengembangan yang digunakan adalah model pengembangan Plomp. Plomp [5] menyatakan karakteristik dari desain bidang pendidikan sebagai metode yang didalamnya orang bekerja secara sistematik menuju ke pemecahan dari masalah yang dibuat. Penelitian pengembangan Lembar Kerja Siswa (LKS) dan Rencana Pelaksanaan Pembelajaran (RPP) yang berbasis Scientific Approach yang berorientasi Problem Based Learning akan dikembangkan untuk mengoptimalkan kemampuan siswa dalam penyelesaian masalah matematika pada kurikulum 2013.

Analisis data yang diperoleh dari validator bersifat deskriptif yang berupa saran komentar. Persentase aktivitas siswa dihitung dengan menggunakan rumus :

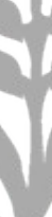

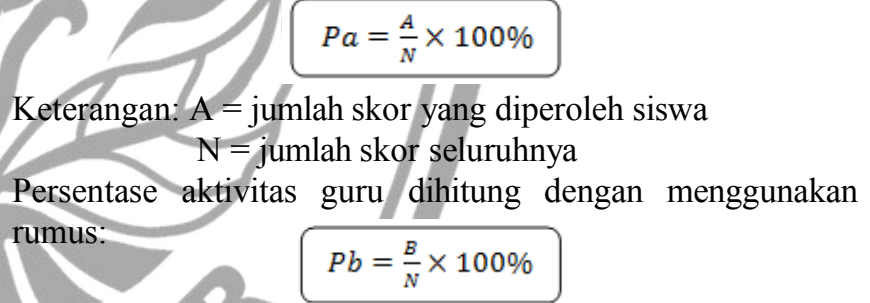

Keterangan: $\mathrm{B}=$ jumlah skor yang diperoleh guru

D $\mathrm{N}=$ jumlah skor seluruhnya

Persentase respon siswa dihitung dengan menggunakan rumus: $\quad P_{r}=\frac{n}{N} \times 100 \%$

Keterangan: $\mathrm{B}$ = jumlah skor yang diperoleh guru $\mathrm{N}=$ jumlah skor seluruhnya

\section{Hasil dan Pembahasan}

Dalam penelitian ini akan perangkat pembelajaran yang dihasilkan meliputi Rencana Pelaksanaan Pembelajaran (RPP), Lembar Kerja Siswa (LKS), dan Tes Hasil Belajar (THB). Dalam pengembangan perangkat pembelajaran perlu diperhatikan bagaimana memunculkan komponen-komponen pembelajaran dengan Scientific Approach dan model pembelajaran Problem Based Learning, terutama dalam mengembangkan RPP dan LKS. Proses mengembangkan RPP dan LKS pada tahap desain juga harus memperhatikan indikator-indikator kualitas perangkat pembelajaran yang dikemukakan oleh O'meara, sehingga diperlukan ketelitian 
dan waktu yang cukup lama dalam proses pembuatan perangkat pembelajaran. Untuk menghasilkan perangkat pembelajaran yang lebih sempurna, perangkat yang telah dibuat harus divalidasi oleh para validator yang kompeten dibidangnya dan direvisi jika masih terdapat kekurangan, kemudian siap untuk diujicobakan pada siswa.

Kriteria-kriteria ketercapaian perangkat pembelajaran yang berbasis Scientific Approach berorientasi Problem Based Learning meliputi kevalidan, kepraktisan dan keefektifan. Perangkat pembelajaran yang meliputi RPP, LKS dan THB dikatakan valid jika koefisien validitas yang memenuhi kriteria interpretasi minimal "tinggi".

(1) RPP

Hasil validasi RPP dari ketiga validator menunjukkan koefisien validasi sebesar 0,91 atau memenuhi kriteria interpretasi sangat tinggi. Hal ini menunjukkan bahwa kriteria kevalidan telah tercapai maka RPP dapat digunakan sebagai pedoman guru untuk melakukan kegiatan belajar mengajar matematika di dalam kelas dengan menggunakan Scientific Approach dan model pembelajaran Problem Based Learning.

(2) LKS

Hasil validasi LKS dari ketiga validator menunjukkan koefisien validasi sebesar 0,93 atau memenuhi kriteria interpretasi sangat tinggi. Dengan demikian LKS dalam penelitian ini dapat dikatakan valid dan layak untuk digunakan oleh guru sebagai media pembelajaran siswa dalam melakukan kegiatan pembelajaran di dalam kelas dengan menggunakan Scientific Approach dan model pembelajaran Problem Based Learning.

(3) Tes Hasil Belajar (THB)

Hasil validasi THB dari ketiga validator menunjukkan koefisien validasi sebesar 0,91 atau memenuhi kriteria interpretasi sangat tinggi. Hal ini menunjukkan bahwa kriteria kevalidan telah tercapai pada THB dan dapat digunakan untuk mengevaluasi kemampuan siswa pada materi perbandingan dan skala setelah melaksanakan pembelajaran matematika berbasis Scientific Approach berorientasi Problem Based Learning.

Hasil uji kepraktisan perangkat pembelajaran berbasis Scientific Approach berorientasi Problem Based Learning didasarkan pada aktivitas guru dalam mengelola pembelajaran di dalam kelas. Dalam kegiatan pembelajaran ini, observasi dilakukan oleh empat observer secara bergantian, pada pertemuan 1 dan 3 kegiatan observasi dilakukan oleh Puguh Wijonarko dan Al Faris P., sedangkan pada pertemuan 2 dan 4 kegiatan observasi dilakukan oleh Dhika Elvira M. dan Arnasyitha Y. Perangkat pembelajaran dikatakan praktis jika persentase aktifitas guru atau memenuhi kategori "baik". Validator mengisi instrumen penilaian aktivitas guru selama pembelajaran berlangsung, selanjutnya hasil dari observasi tersebut akan dianalisis untuk mendapatkan persentase aktivitas guru. Hasil analisis aktivitas guru menunjukkan bahwa pada pertemuan pertama sudah mencapai $90,8 \%$, pertemuan kedua mencapai $89,2 \%$, pertemuan ketiga mencapai $87,5 \%$, dan pertemuan keempat mencapai $90 \%$ dengan kategori baik pada setiap pertemuan. Hal ini menunjukkan bahwa perangkat pembelajaran yang berbasis Scientific Approach berorientasi Problem Based Learning telah memenuhi kriteria kepraktisan perangkat pembelajaran dan guru mampu mengelola pembelajaran dengan baik.

Uji keefektifan perangkat pembelajaran dilakukan dengan menggunakan analisis terhadap observasi aktivitas siswa, tes hasil belajar, dan angket respon siswa. Persentase aktivitas siswa pada pertemuan pertama mencapai $81,3 \%$, pertemuan kedua mencapai $88,5 \%$, pertemuan ketiga mencapai $89,1 \%$, dan pertemuan keempat mencapai $91,1 \%$, sehingga persentase aktivitas siswa pada keempat pertemuan dapat dikategorikan baik. Dari analisis data tes hasil belajar terhadap 32 siswa kelas VII A diperoleh data bahwa nilai tes siswa berkisar antara 62 sampai 100, maka tes hasil belajar telah memenuhi kriteria ketuntasan karena semua siswa mendapatkan nilai diatas nilai minimal yaitu 60. Sedangkan dari analisis angket respon siswa diperoleh persentase sebesar $81 \%$ siswa yang memberi respon positif, artinya siswa senang dengan pembelajaran menggunakan Scientific Approach dan Problem Based Learning maupun dengan media pembelajaran berupa LKS yang berbasis Scientific Approach dan Problem Based Learning. Hal ini menunjukkan bahwa siswa dapat menerima tindakan yang diberikan guru.

LKS dibuat untuk mempermudah siswa dalam memahami materi tentang perbandingan dan skala. Siswa senang dengan penerapan pendekatan pembelajaran Scientific Approach dan model pembelajaran Problem Based Learning. Dan berharap dapat diterapkan pada kegiatan berikutnya. Berdasarkan hasil analisis aktivitas siswa, tes hasil belajar, dan angket respon siswa menunjukkan bahwa uji keefektifan perangkat pembelajaran telah tercapai. Dengan kata lain, peragkat pembelajaran berbasis Scientific Approach berorientasi Problem Based Learning telah memenuhi kriteria keefektifan.

Berdasarkan kriteria-kriteria kualitas perangkat pembelajaran yang telah dipenuhi, dihasilkan perangkat pembelajaran matematika yang meliputi RPP dan LKS berbasis Scientific Approach berorientasi Problem Based Learning materi perbandingan dan skala untuk siswa SMP layak dan dapat digunakan oleh guru tinggkat SMP dalam melaksanakan pembelajaran. RPP digunakan sebagai pedoman dalam melaksanakan pembelajaran matematika di dalam kelas dengan menggunakan pendekatan Scientific Approach dan model pembelajaran Problem Based Learning. LKS dapat digunakan siswa sebagai media pembelajaran untuk membantu siswa memahami materi tentang perbandingan dan skala. Sedangkan THB berbasis masalah hanya digunakan untuk mengukur kemampuan/hasil belajar siswa setelah mengikuti kegiatan pembelajaran.

\section{Kesimpulan dan Saran}

Dari proses dan hasil pengembangan perangkat pembelajaran berbasis Scientific Approach berorientasi Problem Based Learning dapat disimpulkan bahwa pengembangan Lembar Kerja Siswa (LKS) dan Rencana Pelaksanaan Pembelajaran (RPP) materi perbandingan dan skala berbasis Scientific Approach berorientasi Problem Based Learning untuk siswa SMP kelas VII menggunakan model pengembangan perangkat pembelajaran Plomp yang mempunyai 5 tahap, yaitu (1) tahap investigasi awal, (2) 
tahap desain, (3) tahap realisasi/konstruksi, (4) tahap tes, evaluasi, dan revisi, dan (5) tahap implementasi. Produk dari pengembangan ini berupa Rencana Pelaksanaan Pembelajaran (RPP), Lembar Kerja Siswa (LKS), dan Tes Hasil Belajar (THB).

Pengembangan Lembar Kerja Siswa (LKS) dan Rencana Pelaksanaan Pembelajaran (RPP) materi perbandingan dan skala berbasis Scientific Approach berorientasi Problem Based Learning untuk siswa SMP kelas VII mempunyai koefisien validitas sebesar 0,91 untuk RPP; 0,93 untuk LKS; dan 0,91 untuk THB. Tingkat pencapaian aktivitas guru pada pertemuan pertama mencapai $90,8 \%$, pertemuan kedua mencapai $89,2 \%$, pertemuan ketiga mencapai $87,5 \%$, dan pertemuan keempat mencapai $90 \%$ dengan kategori baik pada setiap pertemuan. Persentase aktivitas siswa pada pertemuan pertama mencapai $81,3 \%$, pertemuan kedua mencapai $88,5 \%$, pertemuan ketiga mencapai $89,1 \%$, dan pertemuan keempat mencapai $91,1 \%$, sehingga persentase aktivitas siswa pada keempat pertemuan dapat dikategorikan baik. Dari analisis data tes hasil belajar diperoleh data ratarata ketuntasan hasil belajar $100 \%$ siswa yang mengikuti pembelajaran mampu mencapai tingkat penguasaan materi minimal skor 60 . Sedangkan dari analisis angket respon siswa diperoleh persentase sebesar $81 \%$ siswa yang memberi respon positif. Maka pengembangan Lembar Kerja Siswa (LKS) dan Rencana Pelaksanaan Pembelajaran (RPP) materi perbandingan dan skala berbasis Scientific Approach berorientasi Problem Based Learning telah memenuhi kevalidan, kepraktisan, dan keefektifan.

Berdasarkan proses dan hasil penelitian pengembangan Lembar Kerja Siswa (LKS) dan Rencana Pelaksanaan Pembelajaran (RPP) materi perbandingan dan skala berbasis Scientific Approach yang berorientasi Problem Based Learning muncul beberapa saran agar mempunyai kesiapan yang matang, khususnya dalam instrumen penelitian yang digunakan sehingga waktu yang tersedia bisa digunakan dengan lebih efektif, karena proses penelitian pengembangan merupakan proses yang cukup rumit dan panjang. Perangkat pembelajaran ini hendaknya diuji cobakan juga pada kelas lain atau sekolah-sekolah lain, serta dikembangkan untuk pokok bahasan yang lain, karena berdasarkan pengamatan yang dilakukan pada uji coba hasil belajar siswa meningkat.

\section{Daftar Pustaka}

[1] Masyhud, M. S. 2015. Manajemen Profesi Kependidikan. Yogyakarta: Kurnia Kalam Semesta Yogyakarta.

[2] Depdikbud. 2013. Permendikbud RI Nomor 69 tahun 2013 tentang Kerangka Dasar dan Struktur Kurikulum SMA/MA. Jakarta: Kemendikbud RI.

[3] Depdikbud. 2013. Permendikbud Nomor 81A Tahun 2013 tentang implementasi kurikulum 2013. Jakarta: Kemendikbud RI.

[4] Musaropah, Nuraidah. 2014. Pengembangan Lembar Kerja Siswa Berbasis Pendekatan Scientific pada Sub Tema Gaya dan Gerak. Tasikmalaya: Universitas Pendidikan Indonesia Kampus Tasikalaya.

[5] Rochmad. 2012. Desain Model Pengembangan Perangkat Pembelajaran Matematika. Volume 3, No. 1. Semarang: Jurusan Matematika FMIPA UNNES 